\title{
Introduction: Special Issue on Diversity, Equity, and Inclusion in Education Abroad
}

\section{Guest Co-Editors:}

\section{Eduardo Contreras, Jr.}

University of Portland

\section{Lily López-McGee}

Howard University

David Wick

Middlebury Institute of International Studies at Monterey

\section{Tasha Y. Willis}

California State University, Los Angeles

\section{Special Issue: Background and Goals}

In late 2018, our editorial team set out on a multi-component project to provide a historical reference of established scholarship from Frontiers on diversity, equity, and inclusion in education abroad and to solicit and present a set of new works in this Special Issue on Diversity, Equity, and Inclusion.

We began by creating a special "virtual" issue of existing Frontiers articles centered on diversity, equity, and inclusion, which accompanied our call for papers for this Special Issue on Diversity, Equity, and Inclusion. In our introduction to the virtual issue, we highlighted three gaps in past scholarship on these topics. We noted (a) limited focus on equity and success, (b) a dramatically changed student demographic, and (c) a need for critical examination of education abroad practice in order to make significant strides toward equity. While compiling this virtual issue we were pleased

to see many new initiatives from masters' and doctoral students and from those with whom we corresponded during this process.

With this January 2020 Special Issue, we endeavored to push beyond discussions of access and representation in the field to critically examine inclusion throughout the education abroad process, and to consider equity in outcomes. We hope that the articles we are presenting as the culmination of our work in this Special Issue on Diversity, Equity, and Inclusion will move theory, practice, and scholarship forward.

While our goal was to produce these two issues, the project resulted in a number of realizations for our team about: 
1. the state of research on issues related to diversity, equity, and inclusion in education abroad;

2. the role of access and equity in the article submission and review process;

3. areas of knowledge and training for education abroad professionals that could support the advancement of research in the field, especially as it relates to diversity, equity, and inclusion.

We will expand on each of these as we present the articles and in our discussion of implications and conclusions related to our process and the texts in this Special Issue.

\section{Framing our Introduction as an Ongoing Conversation}

As a result of this project and process, our editorial team approached this introduction to the Special Issue as a continuation of a conversation that we began with our introduction to the Virtual Issue and the Call for Articles. Therefore, our introduction takes an unconventional editorial approach to presenting the articles that we have selected for this Special Issue.

We begin by offering a description of our editorial team's methodology for reviewing and organizing the submissions, and follow with brief descriptions of each piece included in the Special Issue. We then offer a discussion about the implications for practice and scholarship, highlighting key themes we have identified over the course of this endeavor. Subsequently, we provide recommendations for practice and scholarship, offering suggestions on how the field, and scholars in education abroad in particular, could approach topics of equity, inclusion, and diversity in future research.

\section{Modeling Editorial Equity-Mindedness Process and Intent}

In working toward diversity, equity, and inclusion in the pages of Frontiers, we endeavored to model diversity, equity, and inclusion in our editorial process. We strove to do so through several intentional efforts.

As equity-minded editors, we approached our editorial work as facilitators rather than gatekeepers. To this end, we reached out directly to authors of recently published theses and dissertations on relevant topics with the goal of including new and emerging critical voices. We were also deliberate in offering editorial consultation to potential authors to help them shape their work for submission to this Special Issue. In some cases we offered detailed feedback and guidance on full manuscripts and in others we reviewed abstracts. When we received work that was not a good fit for this Special Issue of Frontiers, we recommended alternative venues for submission.

While our actions may all be familiar editorial activities, we hoped that, in combination, and by working collectively from our varied perspectives, we could create and sustain an inclusive process that would result in new voices and perspectives. It should be noted that Frontiers supported our equity-minded approach and noted it was distinctive from other special issues. Frontiers as a journal is considering adopting similar equity-minded approaches for their long-term processes. 


\section{Co-Editor Positionality}

As we thought about the development of diversity, equity, and inclusion research, we emphasized the importance of researcher positionality for several reasons. First, we aimed to reinforce established principles of research. As much as we encouraged authors to situate their arguments within the context of existing literature (when it existed), we also wanted authors to identify and contextualize themselves in a broader social and cultural context.

Just as our identities shaped the ways in which we approached this issue, we believed the authors' identities played an important role in every stage of their research and writing. Beyond this, we were reminded of the formative work of bell hooks (1984), in Feminist Theory: From Margin to Center, who reminded us then that feminist theory had emerged from the privileged women (and men) who lived at the center, yet the reality of the women (and men) who lived at the margins had not been fully incorporated into scholarship. Hooks argued that, as a result of this omission, feminist theory lacked wholeness and could not incorporate a wide array of human experiences. Like hooks, we hoped to bring voices from the margins to the center to add nuance to our understanding of diversity, equity, and inclusion in our field.

\section{Eduardo Contreras, Jr., University of Portland}

I am the Assistant Provost for International Education, Diversity, and Inclusion at the University of Portland, where I also teach courses in the School of Education and College of Arts and Sciences. As a cisgender, white-passing, Latinx male, I go through life with an understanding that my gender and pale phenotypic skin tone grant me distinct privileges within the United States, and within the academy. I also fully experience, on a regular basis, imposter syndrome and stereotype threat within the field of education abroad and within my own predominantly white institution. Having to negotiate my unearned privileges while still navigating my own visibility vis-à-vis those around me in dominant groups guides my approach to my professional work and research.

\section{Lily López-McGee, Howard University}

I have operated at the intersection of international education and equity, inclusion, and diversity for the better part of my career as a practitioner and scholar. As the director of a nationally prestigious fellowship focused on attracting diverse talent to public service, I frequently negotiate ways in which my acquired privileges of location, education, social capital, and class interact with my formative experiences growing up in a low-income, rural, predominantly Latino community. As a white-passing Latina working at a Historically Black College or University situated in Washington, DC, I regularly negotiate my personal and professional identities and engage in self-reflective practices that allow me to integrate different perspectives. These experiences and practices also guide my approach to work and research.

\section{David Wick, Middlebury Institute of International Studies at Monterey}

As an Assistant Professor of international education management, who teaches about diversity, equity, and inclusion, I am very aware of who I am and how I may be perceived. By focusing on equity and social justice in international education, I recognize that through my status as a male, cisgender, white person with an invisible physical disability, I present as someone who only knows privilege in the U.S. context. I seek to confront my privilege through critical self-reflection while 
inviting in the voices and experiences of those around me in order to critically and empathetically collaborate toward equity and social justice in research and practice.

\section{Tasha Y. Willis, California State University, Los Angeles}

Recently minted as an Associate Professor of social work and the current Faculty Director for Internationalization on our Hispanic-serving campus, I am acutely aware of my privilege every day. I teach about intersectionality, racism and other forms of social oppression, equity, diversity, and cross-cultural social work practice while being a cisgender, able-bodied, light-skinned, Black, biracial woman from a middle-class background with a terminal degree and now, tenure. I am also part of Gen X and manage anxiety, imposter syndrome, and the demands of motherhood, and very recently began navigating caregiving for a medically fragile parent. All of these experiences lead me to engage in critical self-reflexivity as I operate in the classroom and in my wider professional roles in international education, educational equity, and social justice.

\section{Our Approach to Content and Form}

Methods for Assessing Content and Considering How the Pieces Fit Together

In response to our Call for Articles, we received dozens of inquiries and submissions. We used the Call for Articles as a rubric with which to assess each question and submission. We considered the thematic topic(s) being addressed, the methodological approach (if research-based), and the grounding in the literature. For each of these elements, we sought to identify work with potential to advance existing knowledge or generate new understandings of diversity, equity, and inclusion in education abroad.

Due to the nature of this topic, and Frontiers' scholar and practitioner audiences, we invited submissions of three types: research articles, case-based exemplars, and critical essays. We believe that each of these types of writing has different potential for advancing scholarship and practice in the field.

At least two members of the editorial team conducted a blind review of each submission. We convened regularly to discuss each submission under consideration. We shared concerns and opportunities related to each article, and discussed how the submissions contributed to the goals of the Special Issue as well as how they fit together.

We discussed and collaboratively drafted our responses so that the authors could hear a unified voice even when they had two reviewers. Throughout this process, our goal was to provide authors with clear and targeted feedback that would help them succeed, while maintaining the integrity of the topic or study and ensuring that the articles presented ideas and connections between themes with a strong grounding in the literature. We also considered which type of writing each submission represented, and we guided authors of selected submissions to refine their work to meet the intent of the three types of writing we sought to include in this Special Issue.

\section{Article Overviews}

\section{Critical Essay}

In preparing this Special Issue, we hoped to include some new ways of thinking about education abroad. In our call for proposals, we described critical essays as "essays that challenge 
underlying assumptions in this field and stimulate critical research, writing, and practice to advance our collective understanding of diversity, equity, and inclusion."

We are pleased to present Stephen Capobianco's article Examining International Education Research and Practice through a Queer Theory Lens. In this critical essay, Capobianco introduces Queer Theory as an analytical lens and uses that framework for a discussion of the current state of education abroad research related to LGBTQI+ students and communities. While we have noticed many workshops and sessions, professional communities, and indeed entire conferences devoted to serving LGBTQI+ education abroad students, we agree with Capobianco that we must do more. We also agree that we must approach research and practice related to LGBTQI+ students from this Queer Theory perspective in order to make progress toward equity for this historically marginalized group.

\section{Case-Based Exemplars}

We find that research- and theory-based approaches to practice can guide us to policies and practices that advance diversity, equity, and inclusion. To this end, we wanted to include case-based exemplars in this issue. These case-based exemplars are "articles that consider best practices and implications for advancing diversity, inclusion, and equity in education abroad that are based on diligent preparation, rigorous design, demonstrable results, and replicable models."

In reviewing submissions, we were struck by how some practitioners are building programs and analysing their practice based on current critical theory and research. The two articles we have selected both include model frameworks and practices that may help us to design and implement programs that are more equitable and just.

In our review of past scholarship, we noticed that few Frontiers authors were examining questions of host community impact in relation to their examination of student growth and development. Eric Hartman, Nora Pillard Reynolds, Caitlin Ferrarini, Niki Messmore, Sabea Evans, Bibi Al-Ebrahim, and John Matthias Brown ground their examination of student and host community interactions and impacts in a large data set and three critical case studies. In their critical essay Coloniality-Decoloniality and Critical Global Citizenship: Identity, Belonging, and Education Abroad, we found that their approach to critically examining global learning and cultural humility, while situating participants in relation to those of the host community, allowed for new ideas about the nature of community-based global learning for students and hosts. We believe that their findings and practices have promise for advancing diversity, equity, and inclusion in the field. We further believe that their work may inspire new directions in scholarship on outcomes of education abroad that balance the needs of and benefits to both home and host communities.

Similar to Hartman et al., in their inclusion of host perspectives, Kenzie Pulsifer, Robert B. Feagan, \& Alicia Sliwinski offer critical insights related to race and nationality in El Salvador through the use of a compelling catalytic moment during a service learning project in their article Race and Participation in International Experiential Learning: Case-Based Exemplar of a Habitat-University Partnership in El Salvador. They present their insights from three perspectives: the vantage point of Canadian students of color, white Canadian students, and members of the El Salvadoran host community. They interpret their findings through a conceptual lens that fuses international experiential learning, Critical Race Theory, and white privilege to address the complicated dynamics at play in the program. The authors highlight the tension created by the convergence of the rise of international 
experiential learning (IEL) in higher education, its roots within colonialism, the racialized construct of north-south relations, and the increasing diversity of education abroad participants.

\section{Research-Based Inquiry}

Our largest pool of articles, in terms of submissions as well as articles ultimately included in this Special Issue, are best categorized as research-based inquiry pieces. We defined these submissions as "pieces that employ a systematic investigation of a topic grounded in theory, existing literature, original and ethical data collection, thoughtful analysis, stimulating conclusions and calls for new research." While each piece had a unique methodology, all four accepted submissions utilized qualitative methods.

In their work Understanding Inclusion and Equity in Community College Education Abroad, co-authors Melissa Whatley and Rosalind Latiner Raby examine the extent to which community college administrators either restrict study abroad to certain students or make these opportunities available to all that express interest. They define the former as exclusive and the latter as inclusive. To answer these questions, they administered a survey collecting both quantitative and qualitative data to leaders in community college education abroad to gain insight into access in education abroad programming at their institutions. Ultimately, Whatley and Raby demonstrate that community colleges are neither fully inclusive nor absolutely exclusive. Their valuable work demonstrates again that inclusion does not naturally follow access-even within institutions like community colleges that are committed to open access. We appreciate how in this study the authors show that some community colleges are beginning to provide more inclusive experiences, yet are not afraid to call community college leaders to action to incorporate more inclusive practices in their education abroad programming.

As we sought to include a range of student experiences, we selected How to Run Together: On Study Abroad and the ASD Experience by Araceli Masterson-Algar, Brian Jennings, and Mark Odenwelder, which provides an important and distinct approach to better understanding the experiences of students with disabilities. The authors explore their experiences leading an education abroad program in two different time periods with two students who identified as having ASD (Autism Spectrum Disorder). The authors take a nuanced approach with rich description that details their experiences as program leaders working with students with ASD, the unique dynamics of accommodating the students' needs, and programming and curricular considerations they took throughout the programs. We felt the authors' focus on moving the conversation surrounding students with disabilities from a purely medical approach to one of student identity and identity development also advances our understanding as education abroad practitioners of how we might reframe how we work with students with disabilities. We see both the methodological approach and the topic of the article as adding a unique element to this Special Issue.

Deepening Convictions: Religious Identity and Off-Campus Study by Kyle David Anderson, Benjamin Knoll, and Ellen Tyra situates religious identity and orientation as an important aspect of the study away experience. While we found that religion has seen increasing attention from the education abroad community (see Frontiers Special Issue on Religion in Study Abroad), we felt this piece explored students' religious identity and orientation in a distinct way by centering the student experience within the context of religiously oriented curricula. We felt the authors' use of four 
distinct programs sought to explore how students' religious identities shaped their experience in their respective programs. Using quantitative and qualitative data, the study used established scales to consider students' religious background, identity, and experiences and their perceptions (favorable/unfavorable) of other religious groups.

One of the areas of scholarship around diversity, equity, and inclusion that we have noted has drawn significant attention in the area of education abroad is that of access to education abroad. While this may be the case, we have also noted that the majority of the work has framed the conversation around access in terms of barriers and what students from underrepresented backgrounds lack. The author of Rewriting the Narrative: An Anti-Deficit Perspective on Study Abroad Participation Among Students of Color, Christel Perkins, has used Yosso's (2005) community cultural wealth model to understand the forms of social capital students of color use in deciding to study abroad, which takes an anti-deficit approach to this line of inquiry. We felt her attempt to center the cultural assets students used to inform their decision to go abroad provided a view of capital that has increasingly gained traction with education abroad practitioners but has remained an understudied domain. We felt the author's approach to the study provides another application of Yosso's (2005) community cultural wealth model that has the potential to advance the conversation of framing the experiences and capital students of color bring with them to the education abroad process as assets rather than deficits.

Each of these research-based inquiry pieces provides thoughtful approaches to and deep synthesis of its respective topic and contributes to our understanding of the nuances of inclusion in education abroad in compelling new ways. In particular, we appreciated how the authors demonstrated that access does not automatically result in inclusion or equity. In every case, the authors demonstrate the interventions, approaches, or policies necessary to produce more inclusive experiences for all students. Most of the articles considered interventions at the individual or program level, notably those by Anderson, Perkins, and Masterson-Algar, Jennings, and Odenwelder, while Whatley and Latiner Raby took a broader look at the institutional level. Despite the differences in scope and unit of analysis, we noted another unifying thread woven through each of these research-based inquiries. Namely, we observed that each of these articles convincingly showed the intentionality necessary at any level to establish and maintain equitable practices. Collectively, we appreciate how these articles provide convincing evidence to support intentional efforts in establishing inclusive and equitable practices in the field.

\section{Book Reviews (1-3)}

During our review process, Anu Taranath's Beyond Guilt Trips: Mindful Travel in an Unequal World was published, and we felt that book reviews of this work would be a relevant addition to our Special Issue. For this purpose, we decided to ask our students to read the book and offer their responses or reflections. You will note that the students' reflections often incorporate their reactions and responses to the way in which the book is written and to Taranath's approach to presenting her material (e.g., personal reflection, non-academic language). The approach that our students used in these reviews is different from the traditional approach to book reviews and adds a dynamic element as we read the pieces. We enjoyed working with these new authors and believe that their ideas and voices both contribute significantly to our understanding of this book and to our scholarpractitioner work as international educators. 
1. Continuing the Conversation: A Response to Anu Taranath's Beyond Guilt Trips: Mindful Travel in an Unequal World, Alexandra Ramos Lopez, Middlebury Institute of International Studies at Monterey.

2. The Importance of Being Conscientious When Traveling Abroad: A Response to Anu Taranath's Beyond Guilt Trips: Mindful Travel in an Unequal World, Karyos Tyus, California State University, Los Angeles.

3. "Hear" We Stand: A Response to Anu Taranath's Beyond Guilt Trips: Mindful Travel in an Unequal World, Lauren Urbina, University of Portland.

\section{Implications for Practice and Scholarship}

In this Special Issue, our aim was to advance the field's understanding of diversity, equity, and inclusion by publishing articles that stimulate critical and constructive conversations. Additionally, as we noted earlier, we were particularly interested in incorporating new voices and perspectives into the Special Issue. While several authors in this Special Issue have contributed to Frontiers by either serving on the editorial board or reviewing manuscripts, all but one are first-time Frontiers authors. The authors also represent a range of institutional types (e.g., public and private colleges/universities, non-profit organizations, education abroad organizations) and varying positions within those institutions, including undergraduate and graduate students, postdoctoral fellows, faculty, and administrators. We are heartened that we were able to achieve our goal and are appreciative to those who submitted their work for consideration, those who encouraged their colleagues to submit their pieces, and the authors who worked closely with Frontiers and our editorial board to adjust and refine the articles.

In considering both the process of curating this Special Issue, and the topics and submission types we received, we noted several implications for practice and scholarship that we invite readers to consider when thinking about diversity, equity, and inclusion in education abroad research and practice.

\section{State of Research on Issues Related to Diversity, Equity, and Inclusion in Education Abroad}

Thematic.

The topics and matters that were addressed in the submissions we received still largely centered on access to education abroad even though we had encouraged different lines of inquiry. While we, too, recognize the demographic differences between the study abroad population and students in higher education, we believe strongly that we must learn more than just who is going and why they do or do not participate.

We are eager to see scholarship on differentiated outcomes between diverse groups of students, issues of power and privilege, which surface in the local context and/or intragroup dynamics, and how this may influence students and host communities. We are curious as well to see how a wider range of critical theoretical frameworks may provide new analysis and insights on myriad aspects of diversity, equity, and inclusion. We believe the interdisciplinary nature of education abroad can create opportunities for practitioners and scholars to call on work outside of the education and international education genre. 
As one example, the work around students with disabilities in education abroad, as MastersonAlgar, Jennings, and Odenwelder pointed out, is largely centered on framing disabilities exclusively using a medical model and we have not yet explored in depth how a student's disability identity can provide insight into their experiences abroad. Scholars such as Glickman (1993) who have focused on moving beyond a medical model to a cultural model of Deaf identity may offer new theoretical models for exploring similar topics in education abroad.

Lines of inquiry.

The majority of articles we received aligned with the research-based inquiry, and this is reflected in the number of pieces included in this Special Issue that employed this approach. There is room for us as a field to utilize the critical essay format to consider how other theoretical models or approaches might be applied to education abroad (e.g., critical feminism, cultural wealth) so as to establish clearer/more unified understanding about how we can employ these models. We noted during this process that two submissions might call on the same theoretical model and interpret its application to education abroad distinctly.

Similarly, while we included two case-based exemplars in this Special Issue, there were fewer of these to consider that exemplified diligent preparation, rigorous design, demonstrable results, and replicable models. Given the importance of home and host context in education abroad work, we believe that case-based exemplars that are rooted in scholarship and critical self-reflection are powerful ways to move scholarship and practice forward.

\section{Role of Access and Equity in the Submission and Review Process}

Areas of knowledge and training for education abroad professionals.

There are areas of knowledge and training for education abroad professionals that could support the advancement of research in the field, especially as it relates to diversity, equity, and inclusion. For example, some professionals may already be well versed in and thus attuned to recognizing historic and present-day power imbalances and inequities that result from structural inequality. However, other colleagues may benefit greatly from training related to how privilege and oppression play out between students and traveling staff or faculty themselves and in the host context. Implications exist on the macro- (systemic), meso- (organizational), and micro(interpersonal) levels. Relatedly, critical self-reflection and reflexivity about the power dynamics at play are crucial among practitioners so we are not unwittingly perpetuating the very tensions we may otherwise explore only in abstract manners. Further, knowledge, sensitivity, and critical selfreflection are important aspects but do not automatically equip us to in turn facilitate difficult discussions and dialogues on the subjects at hand. Instead, dialogue facilitation skills can be taught as an important complement to awareness and sensitivity to power, privilege, and oppression.

Qualitative methodologies.

Several pieces sought to include qualitative data in their analysis, but few employed established approaches to qualitative research design and data analysis. Qualitative research designs provide an excellent opportunity to interrogate the assumptions of what the education abroad experience entails, however, there is a clear need to improve the way in which these methods are employed. There are established qualitative methods that could be appropriately applied to education abroad research (e.g., Koro-Ljungberg, Yendol-Hoppey, Jude Smith, \& Hayes, 2009; Maxwell, 2012; Patton, 
1990), but we as scholars and practitioners in the field need to do the work to learn how to utilize them.

\section{Writing for publication.}

Writing is a skill that often requires practice, support, and feedback. As we considered the submissions, we noted distinct stylistic and technical approaches to writing. While education abroad as a discipline is often embedded in education and psychology, it is also a field where scholars and professionals come with a wide range of education and training (e.g., political science, administration, international affairs) (Lopez-McGee, 2019). Many education abroad practitioners do not arrive versed in the practices of academic writing or have guidance on how to hone their writing skills. We noted during our review that if we as a field are interested in engaging more practitioners and professionals in efforts to develop scholarship, we will need to develop training and professional development focused on honing writing skills for publication, and offering practitioners opportunities to engage in the writing process.

\section{Conclusions}

As we examine this Special Issue of Frontiers, we are humbled by the range of scholars and practitioners who are working on diversity, equity, and inclusion in education abroad. In the work that we have presented here, we believe that we are seeing some new approaches to practice and to scholarship.

\section{Focusing on Success Moves Toward Equity}

Quite significantly, we noted that moving beyond conversations about access or representation led us to see many studies that examine student strengths and community impacts. From the work that these authors have presented, and the ways in which they are grounded, we see tremendous potential for developing new approaches to education abroad that are designed for equity rather than marketed for diversity.

\section{Next Steps for Research Scholarship}

While we believe that this Special Issue moves our scholarly conversations forward, we also see opportunities for future research. We believe that there are many opportunities for investigations related to the experiences and outcomes of the diverse students who study abroad. For example, more attention to a wider array of racial and ethnic groups would yield studies on Latinx, Asian/Southeast, Asian/Pacific Islander, and Native American/Alaska Native students. Also understudied are LGBTQI+ students, students with physical disabilities and/or mental health concerns, and students from spiritual minority groups.

In our Call for Articles, we had solicited submissions that would incorporate more sophisticated methodologies, perhaps from other domains of research, and that could provide additional reference points for international education scholars interested in employing different research strategies. We noted a fairly limited range of research methodologies in the submissions we received (e.g., few critical essays), and while critical research methods often lead to qualitative approaches, we know that there are many opportunities for mixed methods and for quantitative research that can help expand our understanding of diversity, equity, and inclusion in education abroad. For example, the following types of questions could be examined using quantitative or mixed methods: 
- Are there distinct learning outcomes for students from different backgrounds or based on their learning experiences at home or abroad?

- In what ways can education abroad practitioners create programs that are attuned to the needs of a wide array of students?

- What roles do power, privilege, and status play in participation and in determining the level of inclusion and equity in education abroad?

We hope that future research in these domains will employ critical research methods as a mechanism for understanding the complex nature of an education abroad experience.

Another goal of this Special Issue was to incorporate new voices into the body of scholarship. While we are heartened that our process has helped integrate new perspectives into education abroad scholarship, we are also aware that ensuring different perspectives are included takes intentionality, time, and support. As we thought about how best to incorporate a book review of Beyond Guilt Trips, our initial instinct was to identify a colleague or one of our editorial board members to write the piece. We quickly found, however, that our best approach would be to involve the students (undergraduate and graduate) in our networks as a way to both engage them in developing scholarship and help them process their own international and intercultural experiences. We see this process as a model for how other scholars, scholar-practitioners, and editors in the field can create spaces for new voices, introduce young people to the profession, and advance innovative approaches to scholarship in education abroad.

As the field of education abroad continues to work to increase diversity, equity, and inclusion, we believe that it will be essential for scholars and practitioners to deepen their theoretical grounding, hone their research and writing skills, and commit to research-informed practice. We hope that the recommendations we have presented here will contribute positively to these efforts.

\section{References}

Glickman, N. S., \& Carey, J. C. (1993). Measuring deaf cultural identities: A preliminary investigation. Rehabilitation Psychology, 38(4), 275-283. https://doi.org/10.1037/h0080304

hooks, b. (1984). Feminist theory: From margin to center. Cambridge, MA: South End Press.

Koro-Ljungberg, M., Yendol-Hoppey, D., Jude Smith, J., \& Hayes, S. B. (2009). (E)pistemological awareness, instantiation of methods, and uninformed methodological ambiguity in qualitative research projects. Educational Researcher, 38(9), 687-699. doi:10.3102/0013189X09351980

Lopez-McGee, L. (2019). 2019 Survey of diversity and inclusion among international educators. Berkeley, CA: Diversity Abroad.

Maxwell, J. A. (2012). Qualitative research design: An interactive approach (Vol. 41). Thousand Oaks, CA: Sage Publications.

Patton, M. Q. (1990). Qualitative evaluation and research methods. Thousand Oaks, CA: SAGE Publications.

Taranath, A. (2019). Beyond guilt trips: Mindful travel in an unequal world. Lutsen, MN: Between the Lines Publishing. 